\title{
Knowledge of Farmers to Sustainable Agriculture Practices: A Case Study in Southwestern Region of Bangladesh
}

\author{
Mithun Kumar Ghosh ${ }^{1}$, Shaikh Shamim Hasan², Md. Enamul Haque ${ }^{3}$, Md. Jamal Uddin ${ }^{4}$
}

\footnotetext{
${ }^{1}$ Department of Agricultural Extension \& Rural Development, EXIM Bank Agricultural University Bangladesh, Bangladesh

${ }^{2,3}$ Department of Agricultural Extension \& Rural Development, Bangabandhu Sheikh Mujibur Rahman Agricultural University, Bangladesh

${ }^{4}$ National Agriculture Training Academy (NATA), Bangladesh
}

DOI: $10.36347 /$ sjavs.2020.v07i01.002

| Received: 06.12.2019 | Accepted: 13.12.2019 | Published: 10.01.2020

*Corresponding author: Shaikh Shamim Hasan

\section{Abstract}

The agricultural sector is facing major challenges, which can affect the entrepreneurial farming activities. One of the major challenges is the adoption of practices leading to sustainable agriculture. Therefore, it is relevant to investigate the knowledge of the main actors in agriculture: the farmers. The main purpose of this study was to determine the knowledge of the farmers towards sustainable agricultural practices so that the farmers can adopt sustainable agricultural practices more effectively for producing more. So it is needed to ascertain the knowledge of the farmers. Farmers bear knowledge on sustainable agriculture which they acquired from different sources. By this study it was trying to identify that whether the knowledge is sufficient to adopt sustainable agricultural practices. This study was completed through filling up questionnaire by interviewing 90 respondents who were selected using the simple random technique. The major finding of this study was that about $85 \%$ respondents of the study area had low to medium knowledge on sustainable agricultural practices. Therefore the findings suggest that the respondents were not bearing enough knowledge to practice sustainable agriculture.

Keywords: Sustainable agriculture, farmers' knowledge, case study, questionnaire, survey method.

Copyright @ 2020: This is an open-access article distributed under the terms of the Creative Commons Attribution license which permits unrestricted use, distribution, and reproduction in any medium for non-commercial use (NonCommercial, or CC-BY-NC) provided the original author and source are credited.

\section{INTRODUCTION}

Sustainable agriculture may be defined as the effective management of agricultural resources to fulfill human needs, preserve the environment and enhance biological resources [1]. Various researches were conducted on sustainable agriculture that includes three components: economic soundness, environmental protection and social acceptance [2-4]. Bangladesh has an agrarian economy $[5,6]$. Agriculture is the single largest producing sector of the economy since it comprises about $18 \%$ of the country's GDP and employs around 48.4 of the total labor force [8]. The application of modern agricultural science and technology has contributed to increase productivity of agriculture in the last half-century. The successes of agriculture, however, have been accompanied by many ecological problems. Today, both rural and urban inhabitants feel threatened by the dangers posed to the environment by modern agricultural practices such as the heavy use of chemicals. An alternative farming strategy called sustainable agriculture promises remedies to the problems created by industrialized chemical based agriculture, if sustainable agriculture can be shown to be viable and become widely accepted [9].

In recent decades, there has been remarkable growth in agricultural production, with increases in food production across the world since the beginning of the 1960s. Since then, aggregate world food production has grown by $145 \%$. In Africa it rose by $140 \%$, in Latin America by almost $200 \%$ and in Asia by $280 \%$ [10]. Bangladesh agriculture has changed dramatically, especially since the end of the Independence War. Crop productivity soared due to new technologies, mechanization, increased chemical use, specialization and government policies that favored maximizing production [11]. Again, soil fertility is depleted when farmers cultivate crops without returning adequate nutrients to match with the removals. The two strategies are followed in increasing national production, i.e., increasing cropping intensity and increasing yield per crop, place more pressure on soil nutrient reserves. Another cause of concern is the low organic matter content of our soils. Available data show that about $70 \%$ of the net cultivable areas in high and medium highlands have soil organic matter content below $2 \%$. 
So recent changes in agricultural productivity, consumer behavior over food and the political economy of farming and food [12], agricultural systems are now recognized to be a significant source of environmental harm [13-15]. This results in unsustainable agriculture. For transforming this unsustainable agriculture to sustainable agriculture requires farmers to adopt the program.

Not only sustainable agriculture address, many environmental and social concerns, but it offers innovative and economically viable opportunities for growers, laborers, consumers, policy makers and many others in the entire food system with concerning congenial environment.

There are many definitions, none universally accepted. Appropriately, most are concerned with the need for agricultural practices to be economically viable, environmentally considerate and able to meet human food, feed and fiber needs in the long run [1618]. 'Sustainable agriculture' as "farming that makes the best use of natural goods and services while not damaging the environment. It minimizes the use of no renewable inputs (pesticides and fertilizers) that damage the environment or harm the health of farmers and consumers. In addition, it makes better use of the knowledge and skills of farmers" [19]. Sustainability requires a holistic approach in order to understand the whole as an aggregation of interwoven parts working together [20].

Through a study knowledge was identified by as the key factor regarding sustainability [21]. Farmers can be considered as human information processing systems. Human decision-making involves two components [22]. First of all, the farmer's personal characteristics. In this respect, there have been studies regarding the personal characteristics (or traits) that influence farmers in order to adopt or not to adopt specific farming practices [23]. In the second place, there are person's knowledge processes regarding farming practices. With knowledge processes, we mean the processes that individual farmers undertake to understand the information they received.

The ultimate goal or the ends of sustainable agriculture is to develop farming systems that are productive and profitable, conserve the natural resource base, protect the environment, and enhance health and safety, and to do so over the long-term. Considering the above mentioned facts, the study was undertaken with the following objectives:

- To determine the selected socio-demographic characteristics of farmers which influence the farmers knowledge;

- To determine the knowledge of farmers on sustainable agriculture so that they can adopt this practice easily and produce more;
- To explore the individual characteristics of the farmers that may influence their knowledge on sustainable agriculture.

The concept as well as practice of sustainable agriculture and also complexity of it requires individual farmers to possess much knowledge regarding sustainable agricultural systems in order to make them behave in a sustainable way. Moreover, individual farmers require the acquisition of new insights and forgetting old customs that stand in the way of sustainability. So, local farmers' sustainable agricultural knowledge constitutes an extensive realm of accumulated practical knowledge and knowledgegenerating capacities that is needed if sustainability and development goals have to be reached. Therefore, it seems to be relevant to understand what knowledge farmers have about sustainable agricultural practices. It is also relevant to identify the knowledge gap of the farmers to practice this for producing more crops without hampering the environment.

\section{MATERIALS AND METHODS}

Face to face interview method was used using a questionnaire to understand what knowledge farmers have and what farmers do with the information they receive. Lebutala and Ichali union of Jessore Sadar Upazila of Jessore district of Bangladesh were selected as the study location. All farmers of those two unions were considered as the population of this study. The total number of farmers of those two unions was 601 . Out of this population required sample respondents were selected by simple random sampling technique. A total number of 90 farmers (12\% of the population) were selected as a sample. The knowledge of the farmers on sustainable agricultural practices was evaluated using a questionnaire. According to Flick, 2006 [24] this is a method for reconstructing subjective theories. The term "subject theory" refers to the fact that the interviewees have a complex stock of knowledge about the topic under study: sustainable agriculture in our case. This knowledge includes assumptions that are explicit and immediate, and that interviewed farmers are more likely to express spontaneously in an openly designed interview situation than a standardized interview or questionnaire.

\section{Measurement of dependent variable}

Farmers' knowledge on sustainable agriculture was considered as the dependent variable in this study. Knowledge score was computed for each respondent to determine the degree of his awareness and idea on sustainable agricultural practices. Twenty one questions were selected in the interview schedule for measuring farmer's knowledge. Respondent farmers were asked to answer those questions. The score assigned against each item was 2. Weight for responses to the 21 questions of a respondent were added together to get his score on sustainable agricultural practices. Thus, one's sustainable agricultural practices scores could range 
from 0 to 42 , where ' 0 ' indicating 'no knowledge and ' 42 ' indicating very high knowledge'. Based on knowledge score, the respondents were classified into three categories which are low knowledge (up to 20), medium knowledge (21 to 30 ) and high knowledge (more than 30).

\section{Measurement of independent variables}

The independent variables of this study were farmer's age, education, and family size, and farm size, annual income, farming experience, extension contact and cosmopolitan behavior. Age of the respondents was measured on the basis of actual length of his life and expressed in years. The education was measured by the number of years of schooling. Family size was measured by the total number of members, including the respondent himself, spouse, children and other permanent dependents that lived together as a family unit. The total land area possessed by the farmer under farm and homestead was the basis of measuring farm size. The yearly income of the respondent from different sources was the annual income of the respondent. Farming experience was determined by the duration of the experience of a respondent in agricultural works. For measuring extension media contact of the respondent, a four-point scale, i.e, not at all, rarely, occasionally and frequently was used and appropriate weights were assigned to quantify the variable. Respondent's visits to different places outside of his own village were the basis of cosmopolitan behavior measurement.

Necessary tables and categories were used to classify the data considering their nature and distribution. As per the objective of the study, statistical tests like frequency counts, percentage, mean, standard deviation were used for analysis and interpretation of data. Multiple regressions were used and 0.05 and 0.01 level probabilities were used as the basis for exploring the relationship between the socio-demographic characteristics and the knowledge of the farmers throughout the study.

\section{RESULTS AND DISCUSSION \\ Selected characteristics of the farmers}

Data displayed in the Table 1 indicate that the young aged constituted the highest proportion (48.8.\%) of the respondents, followed by middle and old aged category with an average of $38.6 .41 .2 \%$ of the respondents got secondary level education which is the highest, followed by primary level, no education and Tertiary level education.

Table-1: Categories of the selected characteristics of the farmers

\begin{tabular}{|c|c|c|c|c|c|}
\hline Characteristics & Categories & Respondents (\%) & Observed score & Mean & SD \\
\hline Age & $\begin{array}{l}\text { Young } \\
\text { Middle } \\
\text { Old }\end{array}$ & $\begin{array}{l}48.8 \\
35.0 \\
16.2 \\
\end{array}$ & $\begin{array}{l}22 \text { to } \\
65 \text { years }\end{array}$ & 38.66 & 11.24 \\
\hline Education & $\begin{array}{c}\text { No } \\
\text { Primary level } \\
\text { Secondary level } \\
\text { Tertiary level }\end{array}$ & $\begin{array}{c}23.8 \\
35.0 \\
41.2 \\
0\end{array}$ & 0 to 12 & 5.14 & 4.40 \\
\hline Farm size & $\begin{array}{l}\text { Small } \\
\text { Medium } \\
\text { Large }\end{array}$ & $\begin{array}{l}46.2 \\
38.8 \\
15.0\end{array}$ & 0 to 16 & 3.68 & 3.89 \\
\hline Family size & $\begin{array}{c}<3 \text { members } \\
4-5 \text { members } \\
>5 \text { members }\end{array}$ & $\begin{array}{c}10 \\
41.2 \\
48.8 \\
\end{array}$ & 2 to 10 & 5.67 & 1.76 \\
\hline Annual income & $\begin{array}{l}\text { Up to } 40000 \mathrm{tk} \text {. } \\
40001 \text { to } 60000 \mathrm{tk} \text {. } \\
\text { More than } 60000 \mathrm{tk} \text {. }\end{array}$ & $\begin{array}{l}40.8 \\
35.6 \\
23.6 \\
\end{array}$ & $\begin{array}{l}30000 \text { to } \\
110000 \text { tk. }\end{array}$ & 54572.66 & 2805.6 \\
\hline Farming experience & $\begin{array}{c}\text { Low } \\
\text { Medium } \\
\text { High }\end{array}$ & $\begin{array}{l}18.7 \\
45.1 \\
36.2\end{array}$ & 5 to 45 & 20.60 & 10.26 \\
\hline $\begin{array}{l}\text { Cosmopolitan } \\
\text { behavior }\end{array}$ & $\begin{array}{l}\text { Low } \\
\text { Medium } \\
\text { High }\end{array}$ & $\begin{array}{l}43.8 \\
21.2 \\
35.0\end{array}$ & 0 to 40 & 10.67 & 8.84 \\
\hline Extension contact & $\begin{array}{l}\text { Low } \\
\text { Medium } \\
\text { High }\end{array}$ & $\begin{array}{l}81.3 \\
16.3 \\
2.4 \\
\end{array}$ & 1 to 24 & 8.63 & 6.79 \\
\hline
\end{tabular}

The small farm size was 0.2 acres and the largest farm size was 5.26 acres with an average of 3.68 acres. The highest proportion $(46.2 \%)$ of the respondents had small farm size followed by medium and large farm size respectively. The number of family members of the respondents ranged from 2 to 10 , the mean being 5.76, the highest $(48.8 \%)$ proportion fell under more than 5 member's category that is large families. The income of the respondents ranged from Tk. 30000 to Tk. 110000, the average being Tk. 54572.66. Farming experience scores of the respondent could range from 5 to 45 , with an average being 20.60. 
The highest proportion (45.1\%) of the respondent fell in medium experience category, followed by high experience and low experience. The maximum (43.8\%) of the respondents had low cosmopolite behavior followed by $35.0 \%$ had large and $21.2 \%$ had medium cosmopolite behavior with an average of 10.67.Extension contact ranged from 1 to 24 and the average score was 8.63. Most of the respondents (81.3 $\%$ ) had low extension contact followed by medium and high extension contact respectively.

\section{Knowledge on sustainable agricultural practices}

Maintaining soil fertility, enhancing crop productivity through integrated soil fertility and nutrient management is an age-old practice; its importance was not very much realized in the pre-green revolution era due to the low nutrient requirement of the existing subsistence agriculture in Bangladesh. This approach aims for efficient and justified use of all the major plant nutrient sources in a sustainable way, so as to maintain and improve the soil's organic matter for sustained crop productivity. This is all done without any deleterious effect on the physico-chemical and biological properties of the soil on a long term basis [25]. The major components of integrated soil fertility and nutrient management system are fertilizers, farmyard manure/compost, green manure, crop residues/recyclable wastes and bio fertilizers. These components possess a great diversity in terms of chemical and physical properties, nutrient release efficiencies, positional availability, and crop specificity and farmers' acceptability [26]. Integrated soil fertility management and plant nutrient management is an important prerequisite for boosting up crop production and sustaining higher yield over a period of time. Various strategies develop in the future for increasing agricultural production will have to focus on using available natural resources more efficiently, effectively and sustainable than in the past. Since there is no scope to increase the net cultivable land, intensive cropping through integrated soil fertility and nutrient management could be one of the important means to further increase of crop production in Bangladesh [27]. This system helps farmers to take a decision regarding proper way of management which enhances high crop yields and improves the soil fertility in the long run. The farmers of the study area were asked different questions for measuring the knowledge level of them on sustainable agriculture. The questions were asked on four factors (productivity, environmental stability, economic profitability and Social and economic equity) of sustainable agriculture according to. The overall knowledge scores on sustainable agriculture of the respondents range from 8 to 41, with an average being 21.1. Knowledge score on sustainability of the respondents could range from 0 to 42 . By giving correct answer of the questions by the respondents the above mention score was found. On an average the knowledge score was about 21 which mean the respondents gave about $50 \%$ correct answer of the questions on sustainable agricultural practices. The respondents based on their knowledge scores on sustainable agriculture were classified into three categories such as low knowledge, medium knowledge and high knowledge (Figure 1).

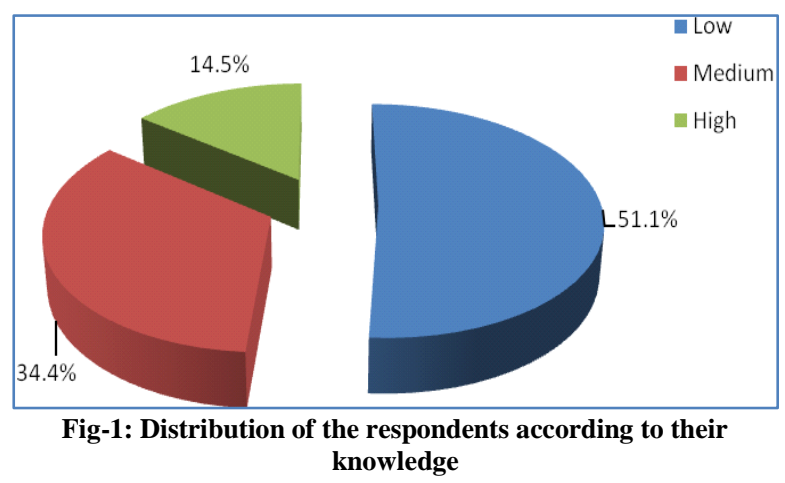

Data furnished in Figure 1 shows that highest proportion $(51.1 \%)$ of the respondents fell in low knowledge category compared to $48.9 \%$ had medium to high knowledge category. Through a study Winter et al, 1995 [28] highlighted that once upon a time when knowledge requirements for environmentally friendly agriculture were confined to particular conservation habitats. A cursory examination of advisory leaflets of two decades ago showed a concentration on how to manage woodlands or plant new ones, how to look after ponds or create them, how best to manage hedgerows for wildlife. In the late 1980s and early 1990s mainstream agricultural practices became increasingly implicated as attention shifted to set-aside management and field and water margins. The above list indicates that the knowledge required for today's environmentally friendly farming is much more likely to have a whole farm focus. Knowledge of any individual increases his/her awareness, mental alertness makes him/her familiar or acquaint with facts, objects, concepts, or practices. Knowledge is quite likely to be inter-linked with education.

Education enables a person to gain knowledge and helps him to become rational which in turn increases his perceptibility. However, it is observed that an overwhelming majority $(85 \%)$ of respondents in the study area had low to medium knowledge on sustainable agriculture. Many respondents of the study area were found to practice sustainable agriculture without having greater formal knowledge. They did it for many years by their own effort. Few of them got training on sustainable agricultural practices from various sources. Some of them had increased their knowledge through watching different TV programs, different agricultural fairs, newspaper, etc. Hence, Government agricultural extension department and other Government Organizations and Non-Government Organizations may give greater emphasis to train to improve their knowledge on sustainable agricultural development. The Department of Agricultural Extension under the Ministry of Agriculture of 
Bangladesh is operating as the main agricultural extension service provider in the country. The department has a huge number of field level extension workers at each Upazila (smaller administrative unit) of the country. They provide all the agricultural related extension services to the farmers, including regular arrangement of training programs for the farmers. Moreover, the department has also some projects which are mostly related to environmental and sustainability issues. So it is possible to improve the knowledge of the farmers on sustainable agricultural practice by being trained up them on these issues.

\section{Factor wise questions distribution of sustainability knowledge}

Lee, 2005 [29], Bhutto and Bazmi, 2007 [30] in their respective study addressed that agriculture plays a vital role in the economy of many developing countries and sustainability in the agricultural sector must address the issues of poverty alleviation, food security, and stable income generation for a rapidly growing population. Ensuring environmental, economic, and social sustainability, farmers must adopt different farm level practices such as judicious use of chemicals, integrated pest management, adequate irrigation, and proper care of plant and animal health. As it is mentioned earlier that in this particular study 21 questions were asked to the respondents to judge the knowledge level of them on sustainable agricultural practice. The questions were distributed factor wise (productivity, environmental stability, economic profitability, social and economic equity) and are presented in Table 2.The findings of this table indicated that farmers had top most knowledge in respect of 'Mention two importance of plant portion present in the field after cutting the crop' where the total score was 178 followed by 'Name two irrigation systems by which water losses reduce' ( score $=175$ ), 'Mention two methods of controlling pests' $($ score $=172)$ and so on.

Table-2: Rank order of the questions about knowledge

\begin{tabular}{|c|c|c|c|c|}
\hline SL. NO. & Questions & Factors & Score & Rank \\
\hline 1. & Can you name two integrated pest control methods? & \multirow{6}{*}{ Productivity } & 145 & 6 \\
\hline 2. & Which two elements that reduce the soil erosion? & & 134 & 7 \\
\hline 3. & Which two techniques of land replenishment? & & 152 & 5 \\
\hline 4. & Can you mention two herbicides that you use in your field for weed control? & & 32 & 20 \\
\hline 5. & . Which elements are essential for plants (mention 2 names) & & 25 & 21 \\
\hline 6. & $\begin{array}{l}\text { Name two crops that increase soil fertility. Which crops increases soil fertility } \\
\text { (mention } 2 \text { names)? }\end{array}$ & & 160 & 4 \\
\hline 7. & Can you mention two ways of water pollution? & \multirow{5}{*}{$\begin{array}{l}\text { Environmental } \\
\text { stability }\end{array}$} & 115 & 10 \\
\hline 8. & Can you mention two sources of air pollution? & & 99 & 11 \\
\hline 9. & Can you mention two bad impact of chemical fertilizer on environment? & & 133 & 8 \\
\hline 10. & How Sustainable agriculture can protect the environment? (Give two examples)? & & 76 & 15 \\
\hline 11. & Can you mention two impacts of deforestation? & & 90 & 13 \\
\hline 12. & How food security is ensured by sustainable agriculture? (give 2 examples only) & \multirow{5}{*}{$\begin{array}{l}\text { Economic } \\
\text { profitability }\end{array}$} & 43 & 18 \\
\hline 13. & $\begin{array}{l}\text { How farm income may be decreased practicing sustainable agriculture (two } \\
\text { examples)? }\end{array}$ & & 82 & 14 \\
\hline 14. & $\begin{array}{l}\text { Can you mention two importance of plant portion present in the field after cutting } \\
\text { the crop? }\end{array}$ & & 178 & 1 \\
\hline 15. & Which two methods are used for controlling pest? & & 172 & 3 \\
\hline 16. & $\begin{array}{l}\text { Name two irrigation systems by which water losses reduce Which two irrigation } \\
\text { systems reduce water loss in the crop fields? }\end{array}$ & & 175 & 2 \\
\hline 17. & What is the definition of sustainable agriculture? & \multirow{5}{*}{$\begin{array}{l}\text { Social and } \\
\text { economic equity }\end{array}$} & 117 & 9 \\
\hline 18. & Can you mention two benefits of Sustainable agriculture? & & 72 & 16 \\
\hline 19. & Can you tell two problems of Sustainable agriculture? & & 50 & 17 \\
\hline 20. & Can you give two reasons for declining ground water level day by day? & & 42 & 19 \\
\hline 21. & What are the two parameters of Sustainable agriculture? & & 91 & 12 \\
\hline
\end{tabular}

'Name two essential elements of plant' was at $21^{\text {st }}$ rank and the total score was 25 in which farmers had lowest knowledge.

\section{Influence of Farmers' Characteristics upon their Knowledge}

This section examines the farmers' characteristics that influence their knowledge of sustainable agricultural practices crop production. Regression results in Table 3 indicate that among eight characteristics that entered into the model, five were found to be statistically significant predictors. These are 1) age; 2) education; 3) farm size; 4) farming experience and 5) cosmopolitan behavior that influence on respondents knowledge of sustainable agricultural practice. 
Table-3: Farmers' Characteristic and Their Influence on knowledge of sustainable agricultural practices

\begin{tabular}{|c|c|c|c|c|}
\hline Variables & Coefficient (b) & SE & $t$-value & $P$ \\
\hline 1. Age* & -0.016 & 0.139 & 2.285 & 0.025 \\
\hline 2. Education ${ }^{* * *}$ & 0.478 & 0.158 & 7.032 & 0.000 \\
\hline 3. Farm size ${ }^{*}$ & -0.025 & 0.164 & -2.293 & 0.024 \\
\hline 4. Family size & 0.033 & 0.330 & 0.486 & 0.628 \\
\hline 5. Income & 0.093 & 0.156 & 0.783 & 0.436 \\
\hline 6. Farming experience ${ }^{*}$ & 0.168 & 0.175 & 2.128 & 0.036 \\
\hline 7. Cosmopolitan behavior ${ }^{* * *}$ & 0.327 & 0.095 & 2.660 & 0.009 \\
\hline 8. Extension contact & -0.063 & 0.128 & -1.100 & 0.275 \\
\hline
\end{tabular}

These variables together explained $63.2 \%$ of the variance of effective factors on farmer's knowledge of sustainable agricultural practices. Explain this means. Farmers who possessed one or more of these characters at a high level were found to have a higher level of knowledge of sustainable agricultural practices; hence they can adopt and practice sustainable agriculture for improving their production level as well as protect the environment. A study was conducted by Sadati et al. [31] in Iran on farmer's attitude on sustainable agriculture and its determinants and found that the 'extension contacts', 'Farmers' knowledge about sustainable agriculture', 'Job satisfaction' and 'literacy' are effective factors on farmer's attitude toward sustainable agriculture and explained $52.6 \%$ of this scale. Through a study Faroque and Takeya [32], found that education level, farming experience, farm size, family size, fertilizer use and communication exposure had an influence on perceptions of integrated soil fertility and nutrient management. Through another study, Hasan et al., [33] found that farmer's age had an influence on the opinion towards floating agriculture. In the developing world, farm size may be considered as an important determinant that directly influences education and other physical facilities that develop knowledge and experience in farming and improved communication skills. Similar types of findings were also found in this study. On the other hand Sadighi [34], also found that through his study on "Assessing Farmers' Sustainable Agricultural Practice Needs: Implication for a Sustainable Farming System" that technical knowledge, age and access to information about the farmers had contributed over farmers sustainable agricultural practice needs. Similarly, at this particular study similar type of findings were found.

On the contrary, one characteristic were identified as significant predictors producing negative regression coefficients. That was: 1) farm size. Respondents who possessed this characteristic that a large sized farm holding had produced less knowledge of sustainable agriculture. Actually in Bangladesh it is more common that farmers with large farm holdings do not operate agricultural practices of their own. They give their land as lease to others. So they bear poor knowledge of sustainable agriculture.

\section{CONCLUSIONS \& RECOMMENDATIONS}

Based on the above findings, the following conclusions were drawn:

- Most of the respondents of the study were younger aged, having large family size, small farm holding and had a secondary level of education with low to medium annual income and medium farming experience. Most of them had low extension contact and low cosmopolitan behavior.

- Half $(50 \%)$ of the respondents had low knowledge on sustainable agriculture compared to $33.8 \%$ having medium and $16.2 \%$ having high knowledge respectively. This might be due to the fact that a considerable proportion of the farmers had not enough training exposure, moderate use of a source of information and low extension contact.

- Multiple regression analysis tests indicated that age, education, farm size, farming experience and cosmopolitan behavior of the farmers had influence on their knowledge of sustainable agricultural practices, that means higher the abovementioned characteristics of the respondent, higher was their response regarding sustainable agriculture. Although these variables together explained $63 \%$ of the variance effective factors on farmers knowledge of sustainable agricultural practices. This implied that still considerable variability in on farmers' knowledge of sustainable agriculture scores could be explained by other variables that were not investigated in this study, which could be the subject of further research in this area.

Based on the conclusions above and practical field observations, the following recommendations are put forward which may be useful for policy planning.

- An integration of soil fertility management and pest management is required to upgrade the sustainability status of the farmer's field of the study area. So the Department of Agricultural Extension (DAE) and other agricultural related departments in the area should give more emphasis to disseminate more information related to sustainable agriculture to the farmers and also should arrange more training for the farmers related to this issue. 
- Proper steps should be taken so that the education status of the farmers can be upgraded. Also information related to sustainable agriculture and integrated nutrient management should be made available to the farmers more so that they can easily adopt this issue.

\section{ACKNOWLEDGEMENTS}

The author was grateful to the Department of Agricultural Extension and Rural Development, Bangabandhu Sheikh Mujibur Rahman Agricultural University (BSMRAU) for their amiable assistance to make the current research successful as well as thankful to authorities of BSMRAU.

\section{REFERENCES}

1. Chikwendu DO, Arokoyo JO. Women and sustainable agricultural development in Nigeria. Journal of Sustainable Agriculture. 1997 Sep 10;11(1):53-69.

2. Fairweather JR, Campbell HR. Environmental beliefs and farm practices of New Zealand farmers Contrasting pathways to sustainability. Agriculture and Human Values. 2003 Sep 1;20(3):287-300.

3. Bell MM, Carolan MS, Mayerfeld D and Exner R. Professional Development for the Adoption of Sustainable Agriculture on Rented Land. Iowa State University, Ames, Iowa.2001.

4. Williams DL. Students' Knowledge of and Expected Impact from Sustainable Agriculture. J. Agric. Educ.2000; 41: 19-24.

5. Sultana S and Hasan SS. Impact of Micro-Credit on Economic Empowerment of Rural Women. TheAgriculturists 2010; 8(2);43-49.

6. Hasan SS, MK Ghosh MS Arefin and Sultana S. Farmers' Attitude Towards Using Agro-Chemicals in Rice Production: A Case in Laxmipur District of Bangladesh. The Agriculturists.2015; 13(2):105.

7. Mohammad, A.H. and Hasan, S.S. 2018. Potentiality of underutilized vegetables for contribution to Sustainable Development Goals (SDGs) in Bangladesh. Asian Journal of Agricultural Extension, Economics \& Sociology.2018; 26(2): 1-9.

8. Anonymous. Yearbook of Agricultural Statistics of Bangladesh. Bangladesh Bureau of Statistics (BBS). Peoples Republic of Bangladesh.2013; 98.

9. Roling NG and MAE. Wagemakers. Facilitating Sustainable Agriculture: Participatory Learning and Adaptive Management in Times of Environmental Uncertainty. Cambridge, United Kingdom: Cambridge University Press; 2002; 125-133

10. FAO. FAOSTAT database. In FAO 2005Rome, Italy: FAO; 2005.

11. ASR. Agriculture Sector Review (Crop sub sector). Actionable Policy Brief and Resource Implications. Ministry of Agriculture; 2006.

12. Goodman D, Watts M, editors. Globalising food: agrarian questions and global restructuring. Psychology Press; 1997.
13. Tilman D. Global environmental impacts of agricultural expansion: the need for sustainable and efficient practices. Proceedings of the National Academy of Sciences. 1999 May 25;96(11):59956000.

14. Pretty JN, Mason CF, Nedwell DB, Hine RE, Leaf S, Dils R. Environmental costs of freshwater eutrophication in England and Wales; 2002.

15. Meyer-Aurich A. Economic and environmental analysis of sustainable farming practices-a Bavarian case study. Agricultural Systems. 2005 Nov 1;86(2):190-206.

16. Crosson PR. Sustainable Agriculture. Quarterly Newsletter, Resources Future 106, pp. 14-17. re, Govt. Republic of Bangladesh, Dhaka.1992; 14-51.

17. USDA. Sustainable Agriculture: Definitions and Terms. Special Reference Briefs Series No. SRB1999; 99-02.

18. Sullivan P. Applying the principles of sustainable farming. National Center for Appropriate Technology, http://attra. ncat. org/attrapub/PDF/Transition. pdf (accessed January 2011). 2003 May.

19. Duesterhaus R. The SWCS view Sustainability's promise. Journal of Soil and Water Conservation. 1990 Jan 1;45(1):4-.

20. Hartfield JL and DL Karlen. Sustainable Agriculture Systems. Boca Raton, FL: Lewis Publishers; 2001.

21. McElroy MW. Social Footprints. Measuring the Social Sustainability Performance of Organizations. Dissertation, University of Groningen; 2008.

22. Newell A and H Simon. Human Problem Solving. Prentice Hall, Englewood Cliffs; 1972.

23. de Lauwere C, Drost H, de Buck A, Smit A, BalkTheuws L, Buurma J, Prins H. To Change or Not to Change? Farmers' Motives to Convert To Integrated or Organic Farming (Or Not). In:Proceedings of ISHS ActaHorticulturae 655: XV nternational symposium on horticultural economics and management, Berlin. 2004; 235-243.

24. Flick U. An introduction to qualitative research. SAG, London, 2006.

25. Gruhn P, Francesco G and Montague, Y. Integrated Nutrient Management, Soil Fertility and Sustainable Agriculture:Current Issues and Challenges. Vision Discussion Paper 32. Washington, D. C.2000; IFPRI.

26. Food and Agriculture Organizations of the United Nations. Guide to Efficient Plant Nutrient Management. Rome, Italy: FAO Land and Water Development Division; 1998.

27. Food and Agriculture Organizations of the United Nations. Land Resource Management. Rome, Italy: FAO Land and Water Development Division; 2004.

28. Winter M, Mills J, Lobley $M$ and Winter $H$. Knowledge for sustainable agriculture. A WWFUK report of Countryside \& Community Research 
Unit, Cheltenham \& Gloucester College of HE, Francis Close Hall, Cheltenham. GL50 4AZ; 1995.

29. Lee DR. Agricultural Sustainability and Technology Adoption: Issues and Policies for Developing Countries. Am. J. Agr. Econ.2005; 87: 1325-1333.

30. Bhutto AW and AA Bazmi. Sustainable Agriculture and Eradication of Poverty in Pakistan. Nat. Resour. Forum. 2007; 31: 253-262.

31. Sadati SA, Fami HS, Asadi A and Sadati SA. Farmer's Attitude on Sustainable Agriculture and its Determinants: A Case Study in Behbahan County of Iran. Research Journal of Applied Sciences, Engineering and Technology.2010; 2(5): 422-427
32. Farouque MG and H. Takeya. Farmers' Perception of Integrated Soil Fertility and Nutrient Management for Sustainable Crop Production: A Study of Rural Areas in Bangladesh. Journal of Agricultural Education.2007; 48(3), 111-122.

33. Hasan, S.S., A. Mohammad, M.K. Ghosh and M.I. Khalil. Assessing of Farmers' Opinion towards Floating Agriculture as a means of Cleaner Production: A Case of Barisal District, Bangladesh. British Journal of Applied Science and Technology.2017; 20(6): 1-14.

34. Sadighi H. Assessing Farmers' Sustainable Agricultural Practice Needs: Implication for a Sustainable Farming System. AIAEE, Proceedings of the 18th Annual Conference, Durban, South Africa; 2002. 